\title{
Reply: What is the preferred therapy for patients with aortic coarctation - The standard gamble and decision analysis versus real results?
}

I N THEIR RESPONSE TO OUR EDITORIAL COMMENT, ${ }^{1}$ Wong et al. ${ }^{2}$ take the position that we have not understood decision analysis, nor the application of the standard gamble method. Instead of simply maintaining the contrary, we shall briefly formulate the essence of our objections to their initial paper. ${ }^{3}$ Decision analysis is a method that can be useful to simulate complicated real life problems. Decision analysis, however, cannot replace clinical decisions, nor should that be suggested, which in our opinion is what Wong et al. did in their paper, ${ }^{3}$ but now implicitly retract in their response. ${ }^{2}$ Moreover, their statement that the data used for the input aspect of their analysis has no impact on the outcome, sheds unfavourable light on their application of decision analysis, not on the method itself.

The data we used from the congenital database of the European Association of Cardiothoracic Surgeons are freely accessible through the internet, ${ }^{4}$ and are thus no secret. The data in that database is submitted anonymously by surgeons who, therefore, are not subjected to the pressures of publication bias. In all likelihood, this data better reflects current day practice than do most published papers, be they peer reviewed or not. If we accept the fact that it is irrelevant that results used in the decision analysis are outdated, then we must question the entire process. If current day surgeons produced the results used by Wong et al. in their analysis, ${ }^{2}$ these very surgeons would at least be fired, if not jailed in real life, which is what this discussion is all about.

The data from the European Association for Cardiothoracic Surgery ${ }^{4}$ deals with mortality, which is the primary endpoint, obviously, of all cardiac operations. Secondary endpoints are of the utmost importance, but irrelevant should the primary endpoint materialise. The weighting given for the secondary endpoints in relation to the primary endpoint is a very personal matter. The

Correspondence to: Prof Dr Tjark Ebels, MD, Department of Cardiothoracic Surgery, University Medical Centre, PO Box 30.001, 9700 RB Groningen, The Netherlands. Tel: +31 50361 3238; Fax: +31 50361 1347; E-mail: T.Ebels@thorax.umcg.nl standard gamble method tries to quantify these personal choices and preferences of patients or parents of children too young to make their own choices. Since these choices deal with the emotions of these very patients, or their parents, it is essential that the interviews used in the standard gamble be held with them, and not with medical or research staff. If the result of the latter, nonetheless, might seem representative, we must deem that to be coincidental.

When Wong et al. ${ }^{2}$ maintain that their analysis is not "an assessment of real life decisions", they are entirely right. Theirs is an analysis based on real life of up to 45 years ago, with dubious application of methodology that produces results with no bearing on real life in 2008 .

Tjark Ebels

Department of Cardiothoracic Surgery

University Medical Centre Groningen the Netherlands

Bobdan Maruszewski

Department of Pediatric Cardiac Surgery Children's Memorial Health Institute

Warsaw, Poland

Eugene H. Blackstone

Department of Thoracic E Cardiovascular Surgery Cleveland Clinic

Cleveland, Obio, United States of America

\section{References}

1. Ebels T, Maruszewski B, Blackstone EH. What is the preferred therapy for patients with aortic coarctation - The standard gamble and decision analysis versus real results? Cardiol Young 2008; 18: 18-21.

2. Wong D, Benson LN, McCrindle BW. Response to Commentary Ebels T, Maruszewski B, Blackstone EH. What is the preferred therapy for patients with aortic coarctation - The standard gamble and decision analysis versus real results? Cardiol Young 2008; 18: in press.

3. Wong D, Benson LN, Van Arsdell GS, Karamlou T, McCrindle BW. Balloon angioplasty is preferred to surgery for aortic coarctation. Cardiol Young 2008; 18: 79-88.

4. European Association for Cardiothoracic Surgery Congenital Database. http://www.eactscongenitaldb.org 